\title{
The Effects of Aerobic Exercise and Melatonin on CA Activity in Rats
}

\section{Elif Şiktar1 ${ }^{1}$, Erdinç Şiktar1 ${ }^{1}$, Yavuz Akkuş ${ }^{1}$}

\author{
${ }^{1}$ Atatürk University, College of Physical Education and Sports, Erzurum-TURKEY
}

\begin{abstract}
The purpose of this study was to determine the effects of Aerobic exercise and Melatonin on carbonic anhydrase activity in rats. In this study, 24 healthy Spraque Dawley male rats, weighing 250-300 g, 4-6 months of age were used. The rats were divided into four equal groups. C; (Control Group), M; (Melatonin Group), E; (Exercise Group), ME, (Melatonin-Exercise Group). The exercise groups (n:12) were run for endurance training at $23^{\circ} \mathrm{C}$. The exercise was caried out 6 days a week for 4 weeks.The intensity of endurance training was gradually increased during four weeks. A standard mild electric shock deterrent was used intermittently when necessary to coerce the rats to run. At the end of the fourth week, rats were killed by decapitation on each training day. According to the result of this study, the level of carbonic anhydrase decreases in control, melatonin and "exercise groups and melatonin decreases significantly in exercise group. As a result, it can be said that melatonin and exercise reduces the level of $\mathrm{CA}$ in mechanisms related to $\mathrm{O}_{2}$ consumption and $\mathrm{CO}_{2}$ production in organism by having an organizer role.
\end{abstract}

Keywords: Melatonin, Carbonic anhydrase, Aerobic Exercise, Rat

\section{INTRODUCTION}

Melatonin, the pineal gland hormone, is secreted in a characteristic circadian rhythm, with its main production occurring during the dark phase. This endogenous rhythm is driven by the suprachiasmatic nuclei, which regulate the activity of $\mathrm{N}$ acetyltransferase (NAT), the rate-limiting enzyme in melatonin biosynthesis. In addition, NAT activity is immediately suppressed by light affecting the retina through a monosynaptic pathway [1]. An increase in Melatonin after strenuous physical exercise has been reported in man, but the results were inconsistent. Recently, an increase in Melatonin was found in rats that had been exposed to hypobaric hypoxia [2]. Moreover, it is considered as a powerful free radical scavenger and likely to be a general promoter of antioxidative mechanisms and apotential antioxidant in vitro and in vivo [1].

The original and primary function of melatonin in organisms is to serve as an antioxidant to detoxify the free radicals generated during the process of aerobic metabolism with the other functions of melatonin[34]. In addition, clinical trials in humans have reported that melatonin effectively reduces the severity of diseases and disorders in which their etiologies are associated with free radical damage or oxidative stress [5-6]. While the results of these experimental and clinical studies clearly document the ability of melatonin to reduce oxidative damage resulting from a variety of oxidative insults in widely different organs, the possibility exists that the protective actions of the indole are related exclusively to its radical scavenging activities as well as to its ability to work in conjunction with other antioxidants via the network described above [7].

Melatonin is known to influence a variety of biological processes including circadian rhythms, neuroendocrine, cardiovascular and immune functions as well as thermoregulation [8-9].

In rats, melatonin through its antioxidant properties, protected the animals from adriamycin-induced nephropathy and cardiomyopathy [10]. Melatonin, because of its antioxidant properties and lipophilic and hydrophilic nature, may be applicable in the treatment of disorders in which oxidative stress is involved, including exercise-induced oxidative stress. The aim of our study is to examine the effect of melatonin in exercise-induced oxidative stress in healthy subjects. Exercise is known to exert numerous physiological changes in vital organ system of the body. Among those changes, the most important is the enhanced respiration and utilization of oxygen in the body. Increased oxygen influx

This article is published under the terms of the Creative Commons Attribution License 4.0

Author(s) retain the copyright of this article. Publication rights with Alkhaer Publications.

Published at: http://www.ijsciences.com/pub/issue/2015-05/

Article Number: V4201505717; Online ISSN: 2305-3925; Print ISSN: 2410-4477 
during exhaustive exercise may be potentially harmful to the body. During the last 10 years, much evidence has accumulated implicating enormous generation of reactive oxygen species and other free radicals especially during exercise in the muscles and heart [11]. Although the exact mechanism for the exercise-induced cell and tissue damage is still elusive, there is an increasing evidence that the enhanced oxidative metabolism associated with the exercise can increase the whole body oxygen consumption 10 to 20 fold [12]. The antioxidant enzyme activities are prone to alteration due to changes in oxygen consumption (oxidative stress). Oxidative stress can be described as a disturbance in the antioxidant system which is not able to adequately scavenge free radicals/reactive oxygen species and arrest lipid peroxidation [11].

Carbonic anhydrase (CA, carbonate hydrolyase, EC 4.2.1.1) is a metalloenzyme. CAs are an important class of enzymes used to regulate $\mathrm{CO}_{2}$ levels in living organisms by catalysing the reversible hydration of $\mathrm{CO}_{2}$ to $\mathrm{HCO}_{3}^{-}$and $\mathrm{H}^{+}$[9-13].

Carbonic anhydrase (CA) isozymes play key roles in diverse processes, such as physiological $\mathrm{pH}$ control and gas balance, calcification, and photosynthesi [14]. However, Carbonic anhydrase (CA; Carbonate hydrolyase, EC 4.2.1.1) is a family of metalloenzymes that catalyze the rapid conversion of carbon dioxide to bicarbonate and protons and involved in the biomineralization process [15]. In the biomineralization process, the mineral structures involved are mainly calcium carbonate and calcium phosphate crystals, in invertebrates and vertebrates, respectively. This enzyme is a multifunctional enzyme that catalyzes the hydration/dehydration of carbon dioxide. The molecular characteristics of the $\mathrm{CA}$ across the plant and animal breeds are similar. 2 It catalyzes the reversible hydration of $\mathrm{CO}_{2}$ to $\mathrm{HCO}_{3}^{-}$ and $\mathrm{H}^{+}$. In the red blood cell, this enzyme is necessary to facilitate the transport of carbon dioxide out of the body [14-16]. Carbonic anhydrase greatly increases the rate of the reaction, with typical catalytic rates of the different forms of this enzyme ranging between 104 and 106 reactions per second.

The active site of most carbonic anhydrases contains a zinc ion. Many natural and synthetic substances can affect the living metabolism by altering enzyme activities and affecting metabolic pathways at low concentrations [17]. CA plays an important role in water and ion transport and $\mathrm{pH}$ regulation in kidney, eye, central nervous system (CNS), inner ear and other systems [15].

So far, many studies have been carried out on the effects of exercise and Melatonin on variables such as growth hormone, etc., but no study has been done on the effects of aerobic exercise and melatonin on carbonic anhydrase activity. Therefore, in the present study we examined the effects of aerobic exercise and melatonin which had previously been shown to protect cellular components from free radical damage on Carbonic anhydrase activity in rats.

\section{MATERIAL AND METHODS \\ Chemicals}

The used melatonin is provided from sigma factory in the form of $1 \mathrm{~g}$ preparate dust. After the dissolution of melatonin in $0.5 \%$ Ethanol rate and by addition of $0.9 \%$ Sodium Chloride, all of the appropriated melatonin groups, were prepared in $50 \mathrm{ml}$ solution form. 1-1.5 hour before begining of exercise and darkness, daily doses $(5 \mathrm{mg} / \mathrm{kg})$ were given intraperitoneally during 4 weeks.

\section{Animals and groups \\ In this study, 24 healthy Spraque Dawley male rats, weighing 250-300 g, 4-6 months of age, provided from Firat University Experimental Animal Research Center (FUDDAM). The study was carried out in Atatürk University Research Center of Experimental Animals and the study was approved by the Ethical Committee of the Atatürk University (AUHADYEK, Ethical Committee Report No: 2008-51). All surgical procedures and protocols used here were in accordance with Guidelines for Ethical Care of Atatürk University Research Center of Experimenta Animals.}

The rats were kept under special conditions and were sheltered in cages, each with 6 rats, at the room temperature $\left(25^{\circ} \mathrm{C}\right)$, supplying with food (Bayramoğlu Yem Sanayi, Erzurum, Turkey) and water for 12-hour day and night cycles. The rats were divided into four equal groups.

C; (Control Group), The sedentary group on which no application was employed.

MC; (Melatonin-Control Group), The ones that were given melatonin, but none were made exhaustive exercise.

E; (Exercise Group), The ones that were made exhaustive exercise.

ME, (Melatonin-Exercise Group), The ones that were given melatonin and were made exhaustive exercise.

\section{Exercise Protocol}

The same exercise programs were applied to exercise and melatonin exercise groups in test groups. During the test, digital thermometer (GEMO, micro software and PID thermo controlled device) was used.

Adaptation Training: For the rats to have adaptation they were made to have exercise on treadmill for 10$15 \mathrm{~min}$, at $20 \mathrm{~m} / \mathrm{min}$ during per week (MAYTME 9805 treadmill exerciser, Commat Ltd., Ankara, Turkey). Adaptation training was made at $23^{\circ} \mathrm{C}$ laboratory temperature. 
Loading Training: The exercise groups (n:12) were exposed to endurance training in laboratories at 23oC. The exercise was done 6 days a week during 4 weeks. Endurance training was gradually increased by increasing the training of speed and time during four weeks. A standard mild electric shock deterrent was used intermittently when necessary to coerce the rats to run. At the end of the fourth week, rats were killed by decapitation on each training day.

\section{The physical training program:}

First week: $\quad$ Time: $30 \mathrm{~min}$; Speed; $(23 \mathrm{~m} / \mathrm{min}$.)

Second week: Time: $40 \mathrm{~min}$; Speed; $(23 \mathrm{~m} / \mathrm{min}$.)

Third week: $\quad$ Time: $50 \mathrm{~min}$; Speed; $(25 \mathrm{~m} / \mathrm{min}$.),

(2\% slope)

Fourth week: Time: $60 \mathrm{~min}$; Speed; $(25 \mathrm{~m} / \mathrm{min}$.), (2\% slope)

Drawing of blood and preparation of haemolysate Venous blood was drawn from the vena cava inferior into a sterile plastic syringe $(10 \mathrm{~mL})$ using a sterile needle. Half of the drawn blood ( $3 \mathrm{~mL})$ was added to a plastic test tube containing $50 \mu \mathrm{L}$ of EDTA (1:100) to be used for the carbonic anhydrase enzyme activity assay. Erythrocytes were isolated from fresh rat blood after exhaustive exercise and hypothermic stress. Immediately, the fresh blood was centrifuged at lowspeed centrifugation $(1500 \mathrm{rpm})$ for $15 \mathrm{~min}$ (HERMLE Z $323 \mathrm{~K}$ ) by removal of plasma and buffy coat. The erythrocyte pellet was washed three times with cold $0.16 \mathrm{M} \mathrm{KCl}$ and the supernatant discarded. One volume of erythrocyte pellet was suspended in five volumes of ice water to give an erythrocyte haemolysate. CA activity was determined colorimetrically as described above [18-19-20].

\section{Protein determination}

Quantitative protein determination was achieved by absorbance measurements at $595 \mathrm{~nm}$ according to Bradford's method (1976), with bovine serum albumin as standard described previously [21-22].

\section{Hemoglobin estimation}

The hemoglobin $(\mathrm{Hb})$ concentration in hemolysate was determined by the cyanmethaemoglobin method. All studies were performed at $+4^{\circ} \mathrm{C}$ [21- 23].

\section{Carbonic anhydrase enzyme activity determination}

Carbonic anhydrase activity was assayed by following the hydration of $\mathrm{CO}_{2}$ at room temperature according to the method described by Wilbur and Anderson (1976). $\quad \mathrm{CO}_{2}$-hydratase activity as an enzyme unit (EU) was calculated by using the equation $\left(t_{o}-t_{c} / t_{c}\right)$ where $t_{o}$ and $t_{c}$ are the times for $\mathrm{pH}$ change of the nonenzymatic and the enzymatic reactions, respectively [14].

\section{Statistical analysis}

The experimental results were performed in triplicate. The data were recorded as mean \pm standard deviation and analyzed by SPSS (version 11.5 for Windows 2000, SPSS Inc.). For determining the mean of two groups different from each other, the Mean-Whitney $\mathrm{U}$ test which is a non-parametric test $(\mathrm{P}<0.05)$ regarded as significant, and $\mathrm{P}<0.001$, very significant is used.

\section{RESULTS}

\section{CA Levels:}

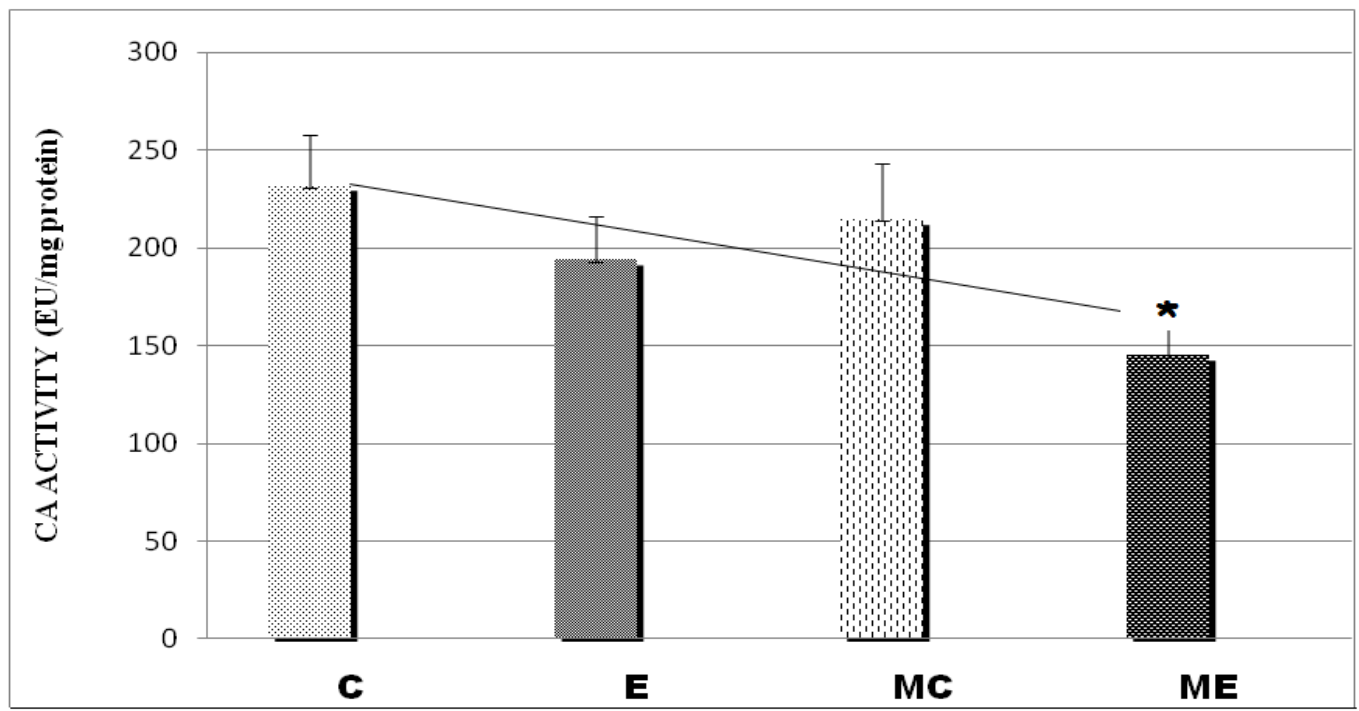

Figure 1. In the graph in which CA levels of Control, Melatonin, Exercise And Melatonin-Exercise Groups are compared, the level of carbonic anhydrase in blood in melatonin-exercise groups is significantly low compared to other groups $(* ; \mathrm{P}<0,05)$, and the highest level of $\mathrm{CA}$ was determined in control group which no application was applied. Data are shown as the mean \pm S.D. for each group. 


\section{DISCUSSION}

Melatonin exists in all body fluids after its release from the pineal gland. It is often utilized, as a sleepinducing agent being an important hormone. The pineal hormone has influence on a variety of biological processes including circadian rhythms, neuroendocrine, cardiovascular and immune functions, as well as for thermoregulation [14]. Additionally, melatonin functions in protecting cell components such as nuclear DNA, membrane lipids and cytosolic proteins from free radical damage [24]. Many chemicals when administered at relatively low doses affect metabolism by altering normal enzyme activity, particularly through inhibition of a specific enzyme. The effects can be dramatic and systemic [25-26]. Therefore, melatonin has an important role by altering the activities of enzymes used to improve the total antioxidative defence capacity of the organism [27]. Its impact on carbonic anhydrase (CA) activity has not previously been reported.

Carbonic anhydrase is a very important enzyme in the body and all the CA isozymes are deeply involved in a great number of secretory activities including fluid movements [9-20]. The physiological function of the $\mathrm{CA}$ isozymes is important in facilitating the interconversion of $\mathrm{CO}_{2}$ and $\mathrm{HCO}_{3}$; also, they play key roles in physiological $\mathrm{pH}$ control in most tissue [28]. Some studies have examined the effects of Melatonin, for example, Beydemir and Gulçin, studied reviews the effects of Melatonin on Carbonic Anhydrase from Human Erythrocytes In Vitro and from Rat Erythrocytes In Vivo. They observed that CA activity in the rat erythrocytes was decreased by the melatonin after 1 and 3 hours. However, CA activity was restored to its normal level after $6 \mathrm{~h}$. probably due to metabolism of the melatonin. The findings indicate that melatonin may be pharmacologically useful in some diseases. HCA-I and HCA-II were purified from human erythrocytes. $\mathrm{CA}$ is widely distributed in most tissues and has a very important role in some diseases such as glaucoma, where CA inhibitors are generally used for treatment since they reduce intraocular pressure. Our study revealed that there was a good correlation between the in vivo and in vitro inhibitory effects of melatonin on HCA-I and HCA-II activities [14]. In another study Kumar et al. studied the effect of oral melatonin on exercise-induced oxidant stress in healthy subjects. The result showed Lipid peroxidation products measured as malondialdehyde - equivalents (MDA-eq) were significantly increased whereas superoxide dismutase and glutathione peroxidase were decreased in subjects after the exercise. There was no change in the total antioxidant activity in plasma or catalase activity in RBC before and after the exercise. The basal levels of lipid peroxidation products were significantly decreased in subjects treated with melatonin as compared with the study without melatonin. The total antioxidant activity was significantly increased in plasma of subjects treated with melatonin. Exercise-induced reduction in superoxide dismutase and glutathione peroxidase was prevented following melatonin treatment [11]. Olcay and colleagues in their study that concluded that Melatonin hormone inhibited the CA of erythrocyte in vivo. Therefore, it may demolish physiological events, i.e. preservation red cell intracellular. $\mathrm{pH}$, ventilatory control and red cell fragility. For this reason, dosage, duration and methods of administrationof melatonin should be further evaluated and excessive applications should be avoided [29].

However, no studies have examined the effects of aerobic exercise and melatonin on carbonic anhydrase activity in rats. Therefore, in this study, the effects of Aerobic exercise and Melatonin on Carbonic anhydrase activity in rats were determined. As a result, the level of carbonic anhydrase decreases significantly in melatonin-exercise group compared to control, melatonin and exercise and melatonin groups. We can say that melatonin and aerobic exercise raise the level of $\mathrm{CA}$, which has a protective part in $\mathrm{O}_{2}$ consumption and $\mathrm{CO}_{2}$ production in organisms and in transferring of $\mathrm{CO}_{2}$ out of tissues and balancing the levels of acid and base in blood and other tissues.

\section{REFERENCES}

1) Frisch, H. Waldhauser, F., Waldhor, T., Müllner-Eidenbock, A., Schweitzer P. and K. (2004). Increase in 6Hydroxymelatonin Excretion in Humans during Ascent to High Altitudes, The Journal of Clinical Endocrinology \& Metabolism 89(9):4388-4390. http://dx.doi.org/10.1210/jc.2003-032214

2) Kaur C, Srinivasan KN, Singh J, Peng CM, Ling EA (2002) Plasma melatoninpinealocyte morphology, and surface receptors/antigen expression on macrophages macrophages/ microglia in the pineal gland following a high-altitude exposure. J Neurosci Res 67:533-543. http://dx.doi.org/10.1002/jnr.10136

3) Hardeland R, Madrid JA, Tandx et al., (2012). Melatonin, the circadian multioscillator system and health: the need for detailed analyses of peripheral melatonin signaling. J Pineal Res 2012; 52:139-166. http://dx.doi.org/10.1111/j.1600079x.2011.00934.x

4) Motilva V, Garcia-Maurino S, Taero E et al., (2011). New paradigms in chronic intestinal inflammation and colon cancer: role of melatonin. J Pineal Res 2011; 51:44-60. http://dx.doi.org/10.1111/j.1600-079x.2011.00915.x

5) Kornatowskak, K., Szewczyk-Golec K, Czuczejko J et al. Effect of melatonin on the oxidative stress in erythrocytes of healthy young and elderly subjects. J Pineal Res 2007; 42:153-158. http://dx.doi.org/10.1111/j.1600079x.2006.00394.x

6) Nickkholgh A, Schneider H, Sobirey M et al., (2011). The use of high-dose melatonin in liver resection is safe: first clinical experience. J Pineal Res 2011; 50:381-388. http://dx.doi.org/10.1111/j.1600-079x.2011.00854.x

7) Dun-Xian Tan, Lucien C. Manchester, Xiaoyan Liu, Sergio A. Rosales-Corral, Dario Acuna-Castroviejo and Russel J. Reiter (2013), Mitochondria and chloroplasts as the original sites of melatonin synthesis: a hypothesis related to melatonin's primary function and evolution in eukaryotes. $\mathrm{J}$ Pineal Res. 2013; 54:127-138. http://dx.doi.org/10.1111/jpi.12026

8) Gülçin I., Mehmet E. Büyukokuroglu, Münir Oktay and O. 
Irfan Kufrevioglu (2002). On the in vitro antioxidative properties of melatonin, J. Pineal Res. 2002; 33:167-171. http://dx.doi.org/10.1034/j.1600-079x.2002.20920.x

9) Beydemir, S., Ciftci, M., Ozmen, I ., Büyükokuroglu, M.E., Ozdemir, H. and Küfrevioglu, O.I. (2000). Effects of some medical drugs on enzyme activities of carbonic anhydrase from human erythrocytes in vitro and from rat erythrocytes in vivo. Pharmacol. Res. 42, 187-191. http://dx.doi.org/10.1006/phrs.2000.0674

10) Moroshima I, Matsui $\mathrm{H}$, Mukawa $\mathrm{H}$, hayashi K, Toki $\mathrm{Y}$, Okumura K, et al (1998). Melatonin: A pineal hormone with antioxidant property protects against adriamycin cardiomyopathy in rats. Life Sci 1998;63:511-21. http://dx.doi.org/10.1016/s0024-3205(98)00302-6

11) Kumar K.Vijay, M.U.R.Naidu (2002), Effect of oral melatonin on exercise-induced oxidant stress in healthy subjects. Indian Journal of Pharmacology 2002; 34: 256-259.

12) Meydani M, Evans WJ(1993). Free radicals, exercise and aging, Yu BP, editor. Free Radical in Aging. Florida: CRC Press; 1993. p. 83-9.

13) Bulbul, M., Hisar, O., Beydemir, S., Ciftci, M. and Kufrevioglu, O.I. (2003) J. The in vitro and in vivo inhibitory effects of some sulfonamide derivatives on rainbow trout (Oncorhynchus mykiss) erythrocyte carbonic anhydrase activity. J. Enz. Inhib. Med. Chem. 18, 371-375. http://dx.doi.org/10.1080/1475636031000138769

14) Beydemir S. and Gulcin I., (2004) Effects of Melatonin on Carbonic Anhydrase from Human Erythrocytes In Vitro and from Rat Erythrocytes In Vivo. Journal of Enzyme Inhibition and Medicinal Chemistry, April 2004 Vol. 19 (2), pp. 193 197. http://dx.doi.org/10.1080/14756360310001656736

15) Coban T.A., Beydemir , S., Gülçin, İ. and Ekinci, D. (2007), Morphine Inhibits Erythrocyte Carbonic Anhydrase in Vitro and in Vivo, Biol. Pharm. Bull. 30(12) 2257-2261. http://dx.doi.org/10.1248/bpb.30.2257

16) Gülçin I., Beydemir S., Alici H. A., Elmastas, M., Büyükokuroglu M. E (2004), In vitro antioxidant properties of morphine. Pharmacol. Res., 49, 59-66.

17) Beydemir S., Çiftçi M., Küfrevioglu O. I., Büyükokuroglu M. E., Effects of gentamicin sulfate on enzyme activities of carbonic anhydrase from human erythrocytes in vitro http://dx.doi.org/10.1248/bpb.25.966

18) and from rat erythrocytes in vivo. Biol. Pharm. Bull., 25, 966-969 (2002). http://dx.doi.org/10.1248/bpb.25.966

19) Rickli, E.E., Ghazanfar, SAS, Gibbons, B.H., Edsall, J.T., (1964). Carbonic anhydrases from human erythrocytes. Preparation and properties of two enzymes. J. Biol. Chem. 239: 1065-1078.

20) Wilbur, K.M., Anderson, N.G., (1976). Electrometric and colorimetric determination of carbonic anhydrase. J. Biol. Chem. 176: 147-151.

21) Hisar, O., Beydemir, S., Gülçin I., O .Irfan küfrevioglu \& Claudiut, Süpüra (2005). Effects of low molecular weight plasma inhibitors of rainbow trout (Oncorhynchus mykiss) on human erythrocyte carbonic anhydrase-II isozyme activity in vitro and rat erythrocytes in vivo. Journal of Enzyme Inhibition and Medicinal Chemistry, February 2005; 20(1): 35-39. http://dx.doi.org/10.1080/1475636040001704461

22) Gülçin I, Beydemir, Ş. And Hisar O (2005). The effect of _tocopherol on the antioxidant enzymes activities and lipid peroxidation of rainbow trout (Oncorhynchus mykiss). Acta Veterinaria Hungarica, 53(4): 425-433. http://dx.doi.org/10.1556/avet.53.2005.4.3

23) Şişecioğlu, M., Çankaya, M., Gülçin, I., Özdemir, M., (2009). The Inhibitory effect of propofol on actoperoxidase. Protein Peptide Lett. 16(1): 46-49. http://dx.doi.org/10.2174/092986609787049394

24) Beydemir, Ş., Gülçin I, Küfrevioglu ÖI, Çiftçi M (2003). Glucose 6-phosphate dehydrogenase: In vitro and In vivo effects of dantrolene sodium. Pol. J. Pharmacol. 55: 787-792.

25) Kim, S.J., Reiter, R.J. and Qi, W (2000). Melatonin prevents oxidative damage to protein and lipid induced by ascorbate -Fe3+-EDTA: comparison with glutathione and $\alpha$ tocopherol.Neuroendocrinol. Lett. 21, 269-276.

26) Hochster, R.M., Kates, M. and Quastel, J.H(1972) Metabolic
Inhibitors (Academic Press, New York), pp 71-89.

27) Hochster, R.M., Kates, M. and Quastel, J.H(1973) Metabolic Inhibitors (Academic Press, New York), pp 66-82.

28) Reiter, R.J., Tang, L., Garcia, J.J. and Munoz-Hoyos, A. (1997). Pharmacological actions of melatonin in oxygen radical pathophysiology. Life Sci. 60, 2255-2271. http://dx.doi.org/10.1016/s0024-3205(97)00030-1

29) Supuran, C.T. and Scozzafava, A. (2002). Applications of Carbonic Anhydrase inhibitors and activators in therapy Exp. Opin. Ther. Pat. 12, 217-242 http://dx.doi.org/10.1517/13543776.12.2.217

30) Olcay H, Beydemir S., Ilhami Gulcin (2009). The Effects of Melatonin Hormone on Carbonic Anhydrase Enzyme Activity in Rainbow Trout(Oncorhynchus mykiss) Erythrocytes In Vitro and In Vivo. Turk J Vet Anim Sci, 29 (2005) http://dx.doi.org/10.1080/1475636040001704461 